\title{
Aortofemoral bypass in occlusive TASC-C and TASC-D lesions: Midterm results of 28 cases
}

\author{
Ekin İlkeliiD, Ali Cemal Düzgün² ${ }^{1}$ \\ ${ }^{1}$ Department of Cardiovascular Surgery, Düzce State Hospital, Düzce, Turkey \\ ${ }^{2}$ Department of Cardiovascular Surgery, Ankara Training and Research Hospital, Ankara, Turkey \\ Received: October 25, 2020 Accepted: December 25, 2020 Published online: March 29, 2021
}

\begin{abstract}
Objectives: This study aims to evaluate the three-year patency rates of aortofemoral bypass surgery in the clinical and radiological diagnosis of Trans-Atlantic Inter-Society Consensus (TASC)-C and TASC-D aortoiliac lesions.

Patients and methods: Medical records of a total of 28 patients (21 males, 7 females; mean age: $64.8 \pm 8.6$ years; range, 58 to 72 years) with TASC-C and TASC-D aortoiliac lesions who underwent aortofemoral bypass surgery between September 2014 and December 2018 were retrospectively analyzed. Demographic and clinical characteristics of the patients were recorded. All operations were performed by a single surgical team by placing a Y graft in the anatomical location and using open median laparotomy technique. The Y graft bypass results with peri- and postoperative data were evaluated.

Results: Dacron Y grafts were used in 18 of TASC-C (25\%) and TASC-D (75\%) lesions, and polytetrafluoroethylene Y grafts were used in 10 of them. No reoperation or amputation was performed in any patient during follow-up. The mean patency of vascular Y grafts was $92 \%$ after three years. There was no significant difference between the graft types and postoperative patient values ( $p>0.05$ ). Mortality was observed in one patient due to systemic inflammatory response syndrome.

Conclusion: The patency of vascular grafts for aortoiliac occlusive disease is satisfactory in TASC-C and D lesions.

Keywords: Aortoiliac occlusive disease, bypass grafting, cardiovascular diseases, vascular prosthesis.
\end{abstract}

Aortobifemoral bypass (ABFB) surgery is usually the most common procedure used in occlusive aortic and iliac artery diseases such as Leriche syndrome. In recent years, minimally invasive, endovascular and laparoscopic interventions and successful surgeries from certain centers have been reported..$^{[1]}$ Advantages of non-open surgical other alternative treatments are low hospital stay, low cost, and faster recovery However, it is important to acknowledge the possible disadvantages of these methods. Certainly, they have less patency rate and do not usually provide complete revascularization. They are less effective in patients with common disease patterns.

Patients usually present with claudication complaints. Some patients present with the complaints of impotence, pain in the hips, and wounds in the feet. Chronic development of atherosclerosis and collateral flow over time may overshadow lower extremity ischemia for a long time and, therefore, these patients remain asymptomatic for a long time.
In the contemporary era, endovascular interventions are more likely to be more than performed ABFB. Despite these changes, perioperative mortality and morbidity remain low with excellent long-term outcomes. In the present study, we aimed to evaluate the operation success rates, three-year primary patency, and complication for Trans-Atlantic Inter-Society Consensus (TASC-C and D aortoiliac lesions treated by surgical anatomic bypass grafting procedure.

\section{PATIENTS AND METHODS}

This single-center, retrospective study was conducted at Ankara Training and Research Hospital between September 2014 and December 2018.

Corresponding author: Ekin İlkeli, MD. Düzce Devlet Hastanesi Kalp ve Damar Cerrahisi Kliniği, 81010 Düzce, Türkiye.

Tel: +90 505 - 6384372 e-mail: ekinilkeli@hotmail.com

\section{Citation:}

İlkeli E, Düzgün AC. Aortofemoral bypass in occlusive TASC-C and TASC-D lesions: Midterm results of 28 cases. Cardiovasc Surg Int 2021;8(1):8-12. 
Medical records of a total of 28 patients $(21$ males, 7 females; mean age: $64.8 \pm 8.6$ years; range, 58 to 72 years) with TASC-C and TASC-D aortoiliac lesions who underwent aortofemoral bypass surgery were retrospectively analyzed. The aortoiliac lesions of the patients were categorized in Table 1 according to the TASC classification. ${ }^{[2]}$ A written informed consent was obtained from each patient. The study protocol was approved by the Ankara Training and Research Hospital Ethics Committee (27.08.2020-357/2020). The study was conducted in accordance with the principles of the Declaration of Helsinki.

Age, sex, comorbidities, type of laparotomy, type of anesthesia, duration of aortic cross-clamp, duration of operation, length of intensive care unit (ICU) and hospital stay, early postoperative complications, blood products used in the operation, antibiotherapy, heparin use, and surgical anastomosis characteristics were recorded. The Y graft types were examined. The $Y$ graft interposition was performed in all patients. Intra- and postoperative complications were recorded.

The patients were evaluated by computed tomographic angiography (CTA) every six months during the first year after the first bypass grafting. In the following years, graft patency was evaluated once with CTA. Ultrasonography was used to control bypass grafts in selected patients.

The graft patency rates, redo operations, complications, and mortality calculations were made from the three-year follow-up data of the patients.

\section{Surgical technique}

All patients were operated in the supine position under general anesthesia. A midline abdominal incision was made and the transperitoneal aorta was approached. Suprailiac aorta and bilateral iliac vessels were exposed, and systemic heparin was administered to all patients before cross clamp. A cross-clamp was placed on the non-calcified part of the aorta in the suprailliac section after heparinization. The proximal anastomosis was made above the iliac bifurcation level with end to side position according to calcification of aortoiliac occlusive disease. Distal anastomosis was performed with an end-to-side fashion to the common femoral arteries just proximal to the bifurcation. Routine activated coagulation time (ACT) control and protamine sodium were not measured after the operation.

\section{Statistical analysis}

Statistical analysis was performed using the IBM SPSS version 22.0 software (IBM Corp., Armonk, NY, USA). Descriptive data were expressed in mean \pm standard deviation (SD), median (min-max) or number and frequency. The Fisher's chi-square test was used to compare Dacron and polytetrafluoroethylene (PTFE) grafts. A $p$ value of $<0.05$ was considered statistically significant.

\section{RESULTS}

Hypertension was seen in $18, \mathrm{DM}$ in 15 , coronary artery disease in 16, peripheral artery disease in six, and chronic obstructive pulmonary disease in eight patients. Of the patients, 14 were smokers. Four of the patients previously underwent coronary artery bypass surgery (Table 2).

Twenty patients were evaluated preoperatively by CTA scanning. Digital subtraction angiography (DSA)

\section{Table 1}

TASC II classification of aortoiliac occlusive disease ${ }^{[2]}$

TASC-A Unilateral or bilateral CIA lesion, unilateral or bilateral stenosis in $\leq 3 \mathrm{~cm}$ EIA.

TASC-B $\leq 3 \mathrm{~cm}$ stenosis in the infrarenal aorta, unilateral CIA occlusion, single/multiple stenoses between 3 and $10 \mathrm{~cm}$ in total in the EIA (not spread to CFA) unilateral EIA occlusion (CFA/IIA origins are not included.

TASC-C Bilateral CIA occlusion, bilateral EIA stenosis $(3-10 \mathrm{~cm}$, not involving CFA), unilateral EIA stenosis (extending to CFA) unilateral EIA occlusion (involves IIA/CFA origins), unilateral calcified EIA occlusion (IIA/CFA involves origins or not

TASC-D Diffuse disease involving infrarenal aortic occlusion, aorta and both iliac arteries requiring treatment diffuse multiple lesion involving unilateral CIA, EIA and CFA. Iliac stenosis in patients with unilateral occlusion, bilateral EIA occlusion, AAA requiring treatment (other lesions not suitable for endograft and requiring open aortoiliac surgery

TASC: Trans-Atlantic Inter-Society Consensus; CIA: Common iliac artery; EIA: External iliac artery; IIA: Internal iliac artery; CFA: Common femoral artery; AAA: Abdominal aortic aneurysm. 


\begin{tabular}{|lcc|}
\hline \multicolumn{4}{|c|}{ Table 2 } \\
\multicolumn{1}{|c|}{ Demographic and clinical characteristics of patients } \\
\hline Sex & $\mathrm{n}$ & $\%$ \\
$\quad$ Male & 21 & 75 \\
$\quad$ Female & 7 & 25 \\
Hypertension & 18 & 64 \\
Diabetes mellitus & 15 & 54 \\
Coronary artery disease & 16 & 57 \\
Peripheral artery disease & 6 & 21 \\
COPD & 8 & 29 \\
Smoking & 14 & 50 \\
Operation history & 4 & 14 \\
Imaging & & \\
$\quad$ Computed angiography & 20 & 71 \\
$\quad$ Digital subtraction angiography & 8 & 29 \\
TASC Classification & & \\
$\quad$ TASC-D & 21 & 75 \\
TASC-C & 7 & 25 \\
\hline COPD: Chronic obstructive pulmonary disease; TASC: Trans-Atlantic \\
Inter-Society Consensus. & & \\
\hline
\end{tabular}

was performed in eight patients. For aortoiliac lesions according to the TASC, $75 \%$ were type D and $25 \%$ were type $\mathrm{C}$ lesions. A Dacron Y graft was used in 18 patients and a PTFE Y graft was used in 10 patients.

All patients were successfully revascularized with graft on anatomical position. The mean operation time was $97 \pm 42 \mathrm{~min}$ and the mean aortic-cross clamp time was $14 \pm 09 \mathrm{~min}$. All patients were followed in the ICU after the operation. The mean length of ICU stay was
$16 \pm 05 \mathrm{~h}$, while the mean length of hospital stay was $4 \pm 08$ days (Table 3 ).

During early follow-up, one patient was reoperated for postoperative bleeding, and three patients underwent reoperation for distal embolism. Surgical embolectomy was performed for all these three patients. Embolectomy was successful in two patients; however, femoropopliteal bypass was required in one patient. One patient died in the early postoperative period due to postoperative systemic inflammatory response syndrome (SIRS).

There was no significant difference between the graft type and operation time, length of ICU and hospital stay, early postoperative complications, blood products used in the operation, and mortality. $(p>0.05)$ A total of 60 units of erythrocyte suspension and 24 units of fresh frozen plasma were used in a total of 28 patients. After the operation, clopidogrel $75 \mathrm{mg}$ once a day and acetylsalicylic acid $100 \mathrm{mg}$ once a day were prescribed as dual therapy for all patients.

The primary patency rates at three years after ABFB were $94 \%$ for the Dacron grafts, and $90 \%$ for the PTFE grafts, respectively $(p>0.05)$. A Y graft thrombosis was observed in two cases. Reoperation and amputation were not performed in any patient during follow-up (Table 4).

\section{DISCUSSION}

Currently, thromboendarterectomy, ABFB, and endovascular intervention options are available in the treatment of aortoiliac occlusive disease. ${ }^{[3]}$

\begin{tabular}{|lcc|}
\multicolumn{2}{c}{$\begin{array}{c}\text { Table 3 } \\
\text { Intraoperative data }\end{array}$} & \\
\hline & Mean & Min-Max \\
\hline Mean operation time (min) & 97.42 & $86-108$ \\
Mean duration of aortic cross clamp (min) & 14.69 & $11-17$ \\
Mean intensive care duration (h) & 16.05 & $10-21$ \\
Mean duration of total hospital stay (day) & 4.08 & $3-6$ \\
Erythrocyte suspension (unit) & 60 & \\
Fresh frozen plasma (unit) & 24 & \\
Reoperation & & \\
$\quad$ Bleeding & 1 & \\
Distal embolism & 3 & \\
Death & 1 & \\
\hline Min: Minimum; Max: Maximum. & & \\
\hline
\end{tabular}




\begin{tabular}{|c|c|c|c|}
\hline \multicolumn{4}{|c|}{$\begin{array}{c}\text { Table } 4 \\
\text { Patency rates according to graft types after three years }\end{array}$} \\
\hline & $\mathrm{n}$ & Primary patency & $\%$ \\
\hline Dacron graft & 18 & 17 & 94 \\
\hline PTFE graft & 10 & 9 & 90 \\
\hline
\end{tabular}

Control of DM, antiplatelet and statin therapy, antihypertensive therapy, quitting smoking and exercise play an important role in medical treatment. It has been reported that cilostazol, a phosphodiesterase III inhibitor, reduces claudication complaints and may be beneficial in providing graft patency and preventing restenosis. ${ }^{[4]}$

The five-year patency rates of aortoiliac bypass grafting vary between 80 and $95.10 \%$ and between 75 and $80 \%$ annually. The Dacron and PTFE bypass surgeries performed in aortic and iliac vessels with large calibration and high flow patterns have excellent long-term results. ${ }^{[5]}$ Randomized multi-center studies have shown no significant difference between the five-year patency rates between both grafts. ${ }^{[6]}$

Arterial autologous grafts are the best choice for revascularization. However, this option for coronary arteries is not available for aorta, iliac, and distal arterial structures. Endovascular interventions have been increasingly used, particularly in peripheral infrainguinal lesions. ${ }^{[7]}$ Currently, endovascular interventions are often preferred to surgery in low-calibrated vascular structures. Endovascular approach has become more preferred, particularly when comorbid diseases and advanced age pose a risk. The results of bypass with artificial grafts in distal peripheral vascular diseases are not satisfactory. Therefore, many vascular surgeons today have adopted endovascular atherectomy, balloon, or stent procedure for more peripheral lesions.

Aortoiliac occlusive disease is often considered as Leriche syndrome. The lesions are classified as Type A, Type B, Type C, and Type D by the TASC. ${ }^{[8]}$ In recent years, widespread stent-balloon applications have been applied to TASC-C and TASC-D lesions. However, the long-term results are still unclear. Although recent studies indicate a patency rate of 60 to $86 \%$, based on all studies, five-year patency rates do not exceed $80 \% .{ }^{[9-11]}$ These results indicate that aortoiliac bypass grafting is still the best revascularization option for TASC-C and TASC-D lesions. In our study, the bypass procedure was successfully applied to all patients. In another study comparing the results of endovascular stenting and bypass grafting in aortoiliac lesions, the authors recommended iliac artery stenting, particularly in elderly and those having severe comorbidities, since the patency rates were lower than surgical treatment. ${ }^{[12]}$ Since the study includes Type B lesions, it can be also considered that the surgical option remains up-to-date in all aortic and iliac lesions. In addition, since unilateral and bilateral lesions were not distributed homogeneously in the study, we consider that stent-balloon results were exaggerated. In laparoscopic vascular surgery, the disadvantages of this technique are the long operation time and insufficient aortic exposure, the inability to place a safe cross-clamp, the use of expensive disposable instruments, excessive aortic calcification, previous abdominal operations and obesity.

Since bypass surgery is mostly performed with artificial grafts, there is a risk of infection, thrombosis, and aneurysm. Many laboratory and clinical studies have been conducted showing that PTFE graft is more resistant to infection. ${ }^{[13]}$ In our study, we did not observe such complications in any of the patients. One of our patients died from SIRS within a few hours after the operation; however, it was not related to a complication of infection.

It is very rare to encounter major complications while open $\mathrm{ABFB}$ surgery. Immediate complications in this surgery are vascular damage, bleeding, intestinal damage, ileus, myocardial infarction, and renal failure. Late complications are aorto-enteric fistula, sexual dysfunction, infection, graft thrombosis and anastomotic pseudoaneurysms. ${ }^{[14]}$

Postoperatively, we reoperated one of our patients for bleeding. However, we could not find the bleeding focus, and $0.25 \mathrm{mg}$ protamine sulfate was administered systemically. The heterogeneous nature of unfractionated heparin, polydispersity of molecular weight or different chemical properties may cause different responses in patients. Therefore, ACT monitoring is required in routine operations. Heparin has advantages due to its short half-life, its ability to be monitored with activated partial thromboplastin time, and to be completely neutralized with protamine sulphate. Since heparin has a short half-life and we follow bleeding drainage, we did not perform postoperative ACT control routinely. 
Cross-clamp time is important in surgical vascular interventions. Insufficient blood supply to the distal arterial vessels can always cause serious ischemic events. It can cause limb loss or amputation. Acute spinal cord ischemia after $\mathrm{ABFB}$ has been reported in the literature. ${ }^{[15,16]}$ In vascular surgery, keeping the ischemia time as short as heparinization time can prevent unpredictable ischemic complications. In our study, the mean operation and cross-clamp time are consistent with the literature. The bypass option is always more advantageous in terms of cost, compared to endovascular treatment. Routine use of the retroperitoneal approach cannot be recommended for standard aortoiliac occlusive disease, although it is advantageous in certain situations. It makes it difficult to tunnel the graft, particularly in patients with obesity.

The main limitations of the present study are the lack of a large sample size and inability to compare the results with endovascular treatment. Further, multi-center, large-scale studies are needed to compare open surgical results with endovascular treatment. In particular, the small sample size of the study limits the generalizability of findings or the ability to provide detailed clinical results.

In conclusion, endovascular interventions are currently performed more commonly than bypass surgery in the treatment of aortoiliac occlusive disease. However, the surgical success and patency rates with $\mathrm{Y}$ graft are still higher in TASC-C and D lesions. As a result, there is no second treatment option that has achieved surgical treatment success in aortoiliac occlusive, bilateral vascular diseases. Open surgical treatment should be the preferred treatment due to long-term patency rate for all patients, except for elderly and those having severe comorbidities.

\section{Declaration of conflicting interests}

The authors declared no conflicts of interest with respect to the authorship and/or publication of this article.

\section{Funding}

The authors received no financial support for the research and/or authorship of this article.

\section{REFERENCES}

1. Krog AH, Sahba M, Pettersen EM, Wisløff T, Sundhagen JO, Kazmi SS. Cost-utility analysis comparing laparoscopic vs open aortobifemoral bypass surgery. Vasc Health Risk Manag 2017;13:217-24.

2. Norgren L, Hiatt WR, Dormandy JA, Nehler MR, Harris KA, Fowkes FG; TASC II Working Group. Inter-Society
Consensus for the Management of Peripheral Arterial Disease (TASC II). J Vasc Surg 2007;45 Suppl S:S5-67.

3. Brown KN, Gonzalez L. Leriche syndrome. In: StatPearls. Treasure Island FL: StatPearls Publishing; 2019.

4. Fakhry F, Spronk S, van der Laan L, Wever JJ, Teijink JA, Hoffmann WH, et al. Endovascular revascularization and supervised exercise for peripheral artery disease and intermittent claudication: A randomized clinical trial. JAMA 2015;314:1936-44.

5. Vartanian SM, Conte MS. Surgical intervention for peripheral arterial disease. Circ Res 2015;116:1614-28.

6. Prager M, Polterauer P, Böhmig HJ, Wagner O, Fügl A, Kretschmer G, et al. Collagen versus gelatin-coated Dacron versus stretch polytetrafluoroethylene in abdominal aortic bifurcation graft surgery: results of a seven-year prospective, randomized multicenter trial. Surgery 2001;130:408-14.

7. Dan K, Garcia-Garcia HM, Hideo-Kajita A, Zhang C, Wermers JP, Kolm P, et al. Paclitaxel-coated balloons and stents for the treatment of peripheral artery disease: proceedings from the Cardiovascular Research Technologies (CRT) 2019 Town Hall. EuroIntervention 2019;15:e317-e319.

8. Gabel JA, Kiang SC, Abou-Zamzam AM Jr, Oyoyo UE, Teruya TH, Tomihama RT. Trans-Atlantic Inter-Society Consensus Class D Aortoiliac Lesions: A comparison of endovascular and open surgical outcomes. AJR Am J Roentgenol 2019;213:696-701.

9. Cvetic V, Sagic D, Koncar I, Kovacevic V, Radmili O, Antonic Z, et al. Endovascular treatment of different types of iliac occlusions-Results from an observational study. PLoS One 2019;14:e0222893.

10. Indes JE, Pfaff MJ, Farrokhyar F, Brown H, Hashim $\mathrm{P}$, Cheung K, et al. Clinical outcomes of 5358 patients undergoing direct open bypass or endovascular treatment for aortoiliac occlusive disease: a systematic review and meta-analysis. J Endovasc Ther 2013;20:443-55.

11. Jongkind V, Akkersdijk GJ, Yeung KK, Wisselink W. A systematic review of endovascular treatment of extensive aortoiliac occlusive disease. J Vasc Surg 2010;52:1376-83.

12. Benetis R, Kavaliauskiene Z, Antusevas A, Kaupas RS, Inciura D, Kinduris S. Comparison of results of endovascular stenting and bypass grafting for TransAtlantic Inter-Society (TASC II) type B, C and D iliac occlusive disease. Arch Med Sci 2016;12:353-9.

13. Açıkel Ü, Karabay Ö, Silistreli E, Turan A, Oto Ö. Minilaparatomi tekniği ile aortobifemoral bypass ameliyatları: 4 olgu sunumu. GKDC Dergisi 1998:6:155-9.

14. Batt M, Jean-Baptiste E, O'Connor S, Saint-Lebes B, Feugier P, Patra P, et al. Early and late results of contemporary management of 37 secondary aortoenteric fistulae. Eur J Vasc Endovasc Surg 2011;41:748-57.

15. Türköz R, Deniz B, Kestelli M, Özbek C, Akçay A, Tonguç E, et al. Aortobifemoral bypass olgularında dakron ve politetrafloroetilen greftin karşılaştırılması. GKD Cer Derg 1997:5:212-7.

16. Kouki S, Labben E, Abdallah NB. Acute spinal cord infarction after aortobifemoral bypass. Neurol India 2017;65:1128-30. 